\title{
Is the lymph node ratio superior to the Union for International Cancer Control (UICC) TNM system in prognosis of colon cancer?
}

\author{
Leif Schiffmann*, Anne Karen Eiken, Michael Gock and Ernst Klar
}

\begin{abstract}
Background: Decision making for adjuvant chemotherapy in stage III colon cancer is based on the TNM system. It is well known that prognosis worsens with higher $\mathrm{pN}$ classification, and several recent studies propose superiority of the lymph node ratio (In ratio) to the TNM system. Therefore, we compared the prognosis of In ratio to TNM system in our stage III colon cancer patients.

Methods: A total of 939 patients underwent radical surgery for colorectal cancer between January 2000 and December 2009. From this pool of patients, 142 colon cancer stage III patients were identified and taken for this analysis. Using martingale residuals, this cohort could be separated into a group with a low In ratio and one with a high In ratio. These groups were compared to pN1 and pN2 of the TNM system.

Results: For In ratio, the cutoff was calculated at 0.2. There was a good prognosis of disease-free and cancer-related survival for the N-category of the TNM system as well as for the lymph node ratio. There was no statistical difference between using the N-category of the TNM system and the In ratio.

Conclusions: There might not be a benefit in using the lymph node ratio rather than the N category of the TNM system as long as the number of subgroups is not increased. In our consideration, there is no need to change the $\mathrm{N}$ categorization of the TNM system to the In ratio.
\end{abstract}

Keywords: Colon cancer, TNM system, In ratio

\section{Background}

Colorectal cancer (CRC) is one of the most important causes of cancer-related death in the western world. In Germany, approximately 71,400 patients develop CRC per year [1]. Most cancer related deaths are not caused by the primary cancer site, but by distant metastasis. However, patients without distant metastasis at the time of surgery (UICC I to III) still have improvable 5-year survival rates between $41 \%$ and $96 \%[2,3]$.

Adjuvant or palliative (radio) chemotherapy is generally recommended for UICC III and IV tumors despite the associated toxicities [4,5]. Patients' outcomes vary widely between stages with a worsen outcome from stage I to IV, but also within each stage. So far, indication for adjuvant therapy is based on the TNM system

\footnotetext{
* Correspondence: leif.schiffmann@med.uni-rostock.de

Department of General, Thoracic, Vascular and Transplantation Surgery, University of Rostock, Schillingallee 35, Rostock 18057, Germany
}

and therefore basically on the lymph node status. Several recent studies propose superiority of the lymph node ratio (ln ratio) to the TNM system in prognosis of colorectal cancer [6-11]. The ln ratio is the ratio of the number of positive nodes to the total number of nodes excised. In this study we compared retrospectively the prognosis of $\ln$ ratio to TNM system in our stage III colon cancer patients in terms of disease-free survival (DFS) and cancer-related survival.

\section{Methods \\ Patients}

From January 2000 to December 2009, 939 patients underwent radical surgery for CRC in the Department of General, Thoracic, Vascular und Transplantation Surgery. All patients were treated according to standard treatment guidelines [12]. A preoperative anesthesiological evaluation was obtained according to the American Society of

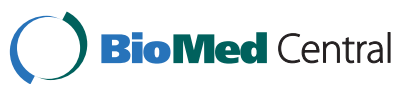


Anesthesiologists (ASA) general classification [13] to determine state of health and comorbidity. Preoperative staging involved endoscopy and biopsy, abdomen ultrasound and chest radiography or computer tomography of abdomen, chest or both.

Patients were staged according to the TNM system [14]. Clinical data were retrieved retrospectively. Data recorded included gender, type of admission, comorbidities, ASA score, tumor characteristics, type of resection, morbidity and 30-day mortality. Follow-up information was recorded regarding recurrence and distant metastasis, overall survival and cancer-related survival as well as information about adjuvant therapy in early 2011. Follow-up examinations were carried out in cooperation with the referring physicians according to the German S3 guidelines for colorectal cancer [12] and provided a comprehensive and complete data collection.

From this pool of patients, all 142 patients with stage III colon cancer were identified and included in this study.

The study was approved by the Medical Ethical Committee of Rostock University.

\section{Comparing lymph node ratio to $N$ category of the TNM system and statistical analysis}

To be able to compare the $\mathrm{N}$ category of the TNM system to the ln ratio, we decided to separate the ln ratio of all patients into two groups. Therefore, martingale residuals [15] were calculated and represented by a smoothed residual plot [16] to determine if and which cutoff value of the ln ratio would allow the best separation of the groups of patients with worse and better survival.

Statistical analysis was performed using Statistical Package for Social Science $\left(\right.$ SPSS $^{\mathrm{TM}}$ ) version 15.0. (www. spss.com). Statistical analysis was done using Pearson's chi-square test of Fisher's exact test. Survival curves were calculated according to the Kaplan-Meier method. Survival curves were tested for significant differences using the log-rank test. A $P$ value of $<0.05$ was considered as statistically significant. Additionally, further analysis was preformed for the $\mathrm{N}$ category of the TNM system and the ln ratio.

\section{Results}

From 939 patients a cohort of 142 stage III colon cancer patients was identified. Patients and tumor characteristics are shown in Table 1 . On average, there were 23.2 lymph nodes harvested and of these, 4 lymph nodes tested positive for metastasis. In the specimens of 13 patients, fewer than 12 lymph nodes were analyzed. Follow-up time was slightly less than 4 years (mean), and just about one-third of all patients developed recurrence of cancer; $30 \%$ of ALL patients died.
Table 1 Patients' and tumor characteristics of the 142 patients included in the analysis

\begin{tabular}{|c|c|c|}
\hline \multirow{3}{*}{$\begin{array}{l}\text { Mean age (years), (range) } \\
\text { Gender ratio }(f / m)\end{array}$} & \multicolumn{2}{|c|}{142 Patients (\%) } \\
\hline & \multicolumn{2}{|c|}{70.0 (37 to 94$)$} \\
\hline & $1: 1$ & $(50: 50)$ \\
\hline \multicolumn{3}{|l|}{ Localization } \\
\hline Cecum & 19 & (13.4) \\
\hline Right hemicolon & 37 & $(26.1)$ \\
\hline Transverse colon & 20 & $(14.1)$ \\
\hline Left hemicolon & 8 & (5.6) \\
\hline Sigmoid colon & 58 & $(40.8)$ \\
\hline Comorbidities & 117 & $(82.4)$ \\
\hline Emergency surgery & 25 & (17.6) \\
\hline \multicolumn{3}{|l|}{ ASA Score } \\
\hline 1 to 2 & 71 & $(50.0)$ \\
\hline 3 to 4 & 71 & $(50.0)$ \\
\hline \multicolumn{3}{|l|}{ Tumor characterization } \\
\hline $\mathrm{T} 1$ & 3 & $(2.1)$ \\
\hline $\mathrm{T} 2$ & 14 & (9.9) \\
\hline T3 & 64 & $(45.1)$ \\
\hline T4 & 61 & $(43.0)$ \\
\hline $\mathrm{R} 1 / 2$ & 10 & $(7.0)$ \\
\hline N1 & 80 & $(56.3)$ \\
\hline N2 & 62 & $(43.7)$ \\
\hline Lymph nodes examined & 23.16 & \pm 9.33 \\
\hline Lymph nodes positive & 4.04 & \pm 4.15 \\
\hline Vo & 73 & (51.4) \\
\hline LO & 76 & (53.5) \\
\hline $\mathrm{G} 1 / 2$ & 111 & $(78.2)$ \\
\hline Adjuvant chemotherapy & 126 & $(88.7)$ \\
\hline Follow-up (years) & 3.85 & \pm 2.81 \\
\hline Recurrence & 48 & (33.8) \\
\hline Died of disease & 43 & $(30.3)$ \\
\hline
\end{tabular}

ASA, American Society of Anesthesiologists.

Estimated cancer-related 5-year survival was $66.8 \%$ and estimated 5-year disease-free survival was $64.2 \%$.

To determine, if there was a potential benefit of calculating the lymph node ratio rather than using the $\mathrm{N}$ category of the TNM system, we separated the patient cohort into two groups of lymph node ratios using the martingale residuals analog to the two groups of the $\mathrm{N}$ category of the TNM system. The cutoff was at 0.2 positive to all examined lymph-nodes (shown in Figure 1).

A total of 88 patients had a lymph node ratio below 0.2 , but only 80 patients had an N1 category. There was a good prognosis of disease-free and cancer-related survival for the $\mathrm{N}$ category of the TNM system (Figures 2 and 3 ) as well as for the lymph node ratio (Figures 4 and 


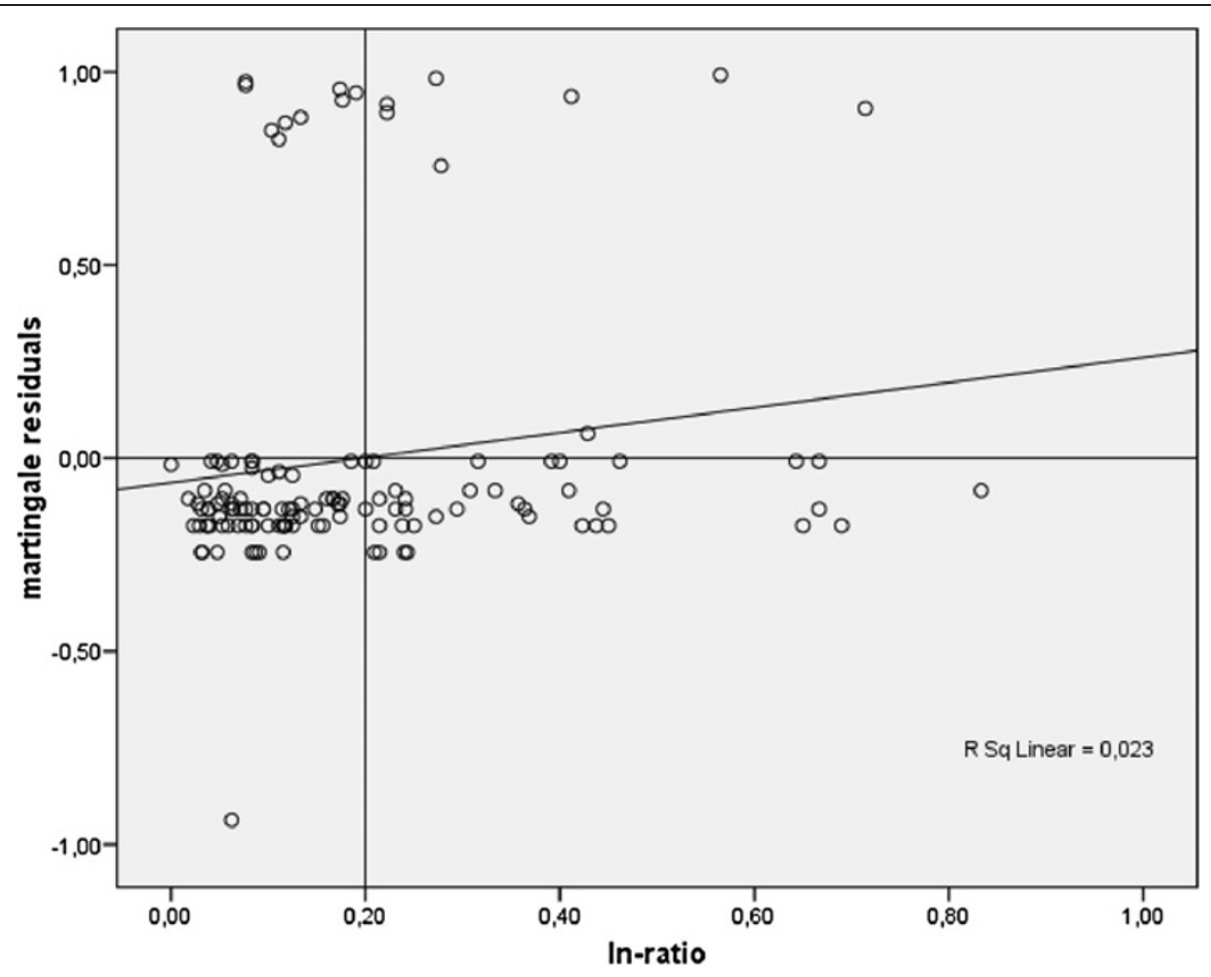

Figure 1 Martingale residuals as a function of the lymph node ratio. Each dot represents the difference between the observed individual status and the calculated cumulative risk at the end of the observation period.

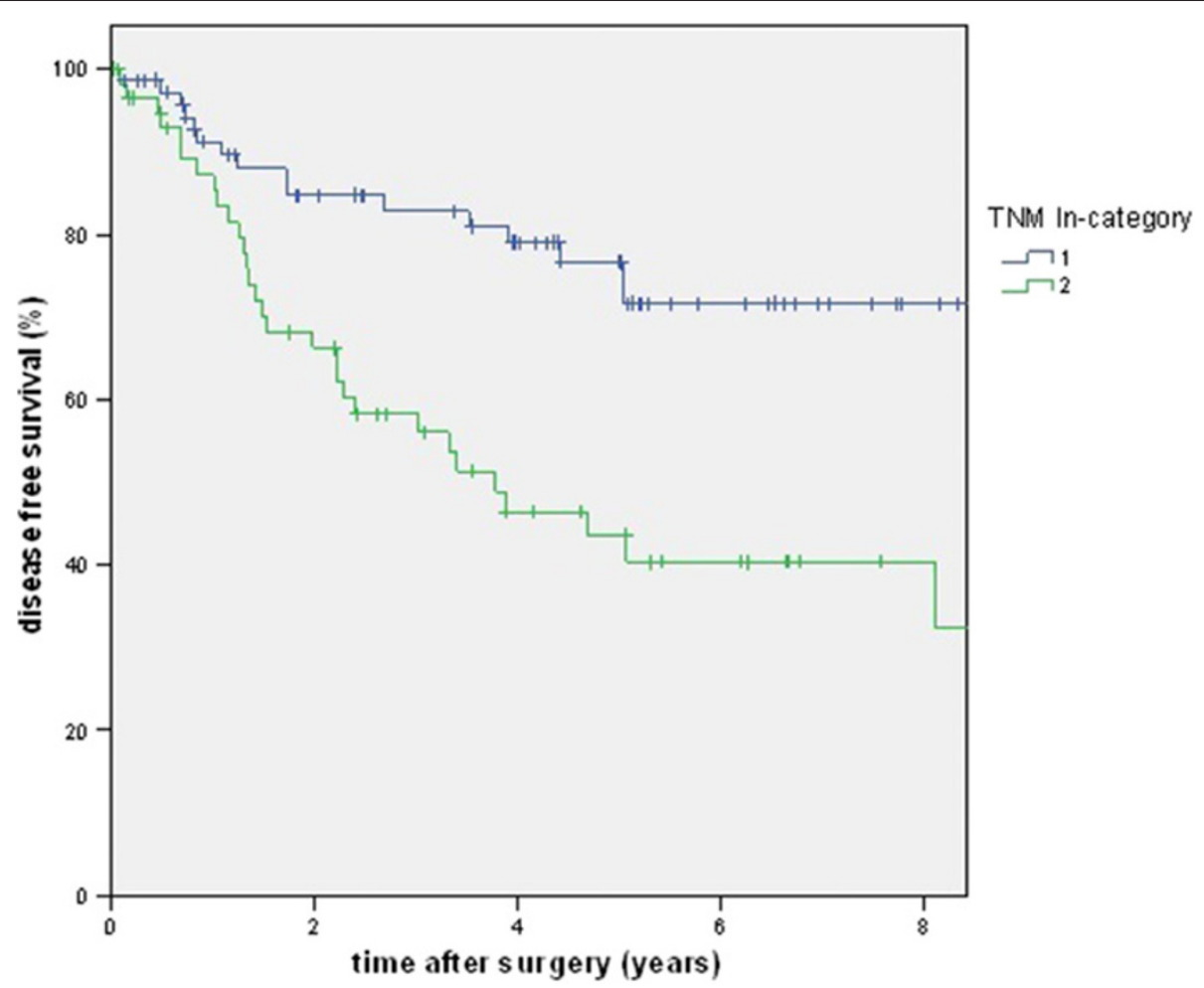

Figure 2 The figure shows the disease-free survival stratified by pN category. With a higher stage (pN2) disease-free survival (DFS) becomes worse $(P<0.001)$. 


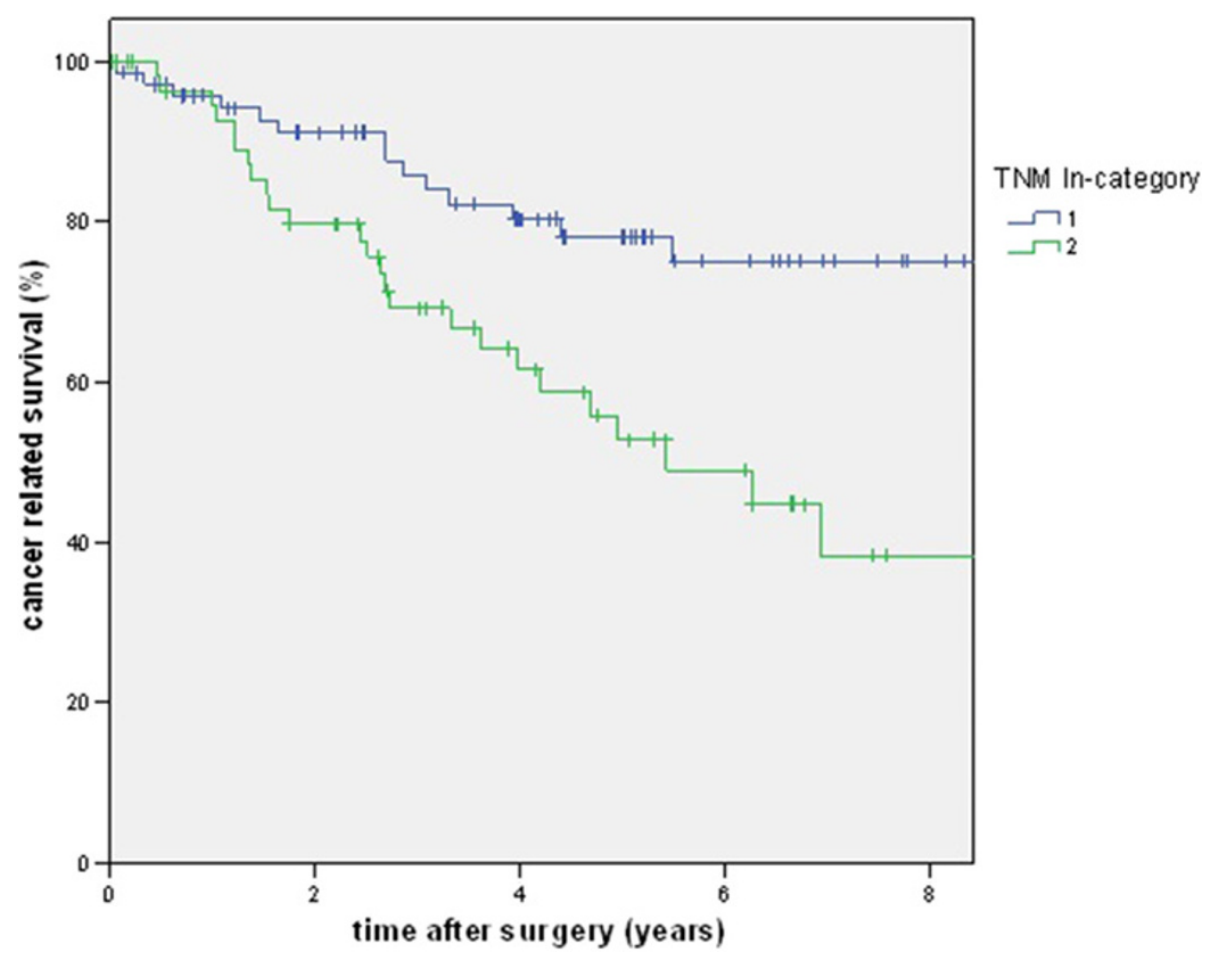

Figure 3 The figure shows the cancer-related survival stratified by pN category. With a higher stage (pN2) cancer-related survival becomes worse $(P=0.002)$

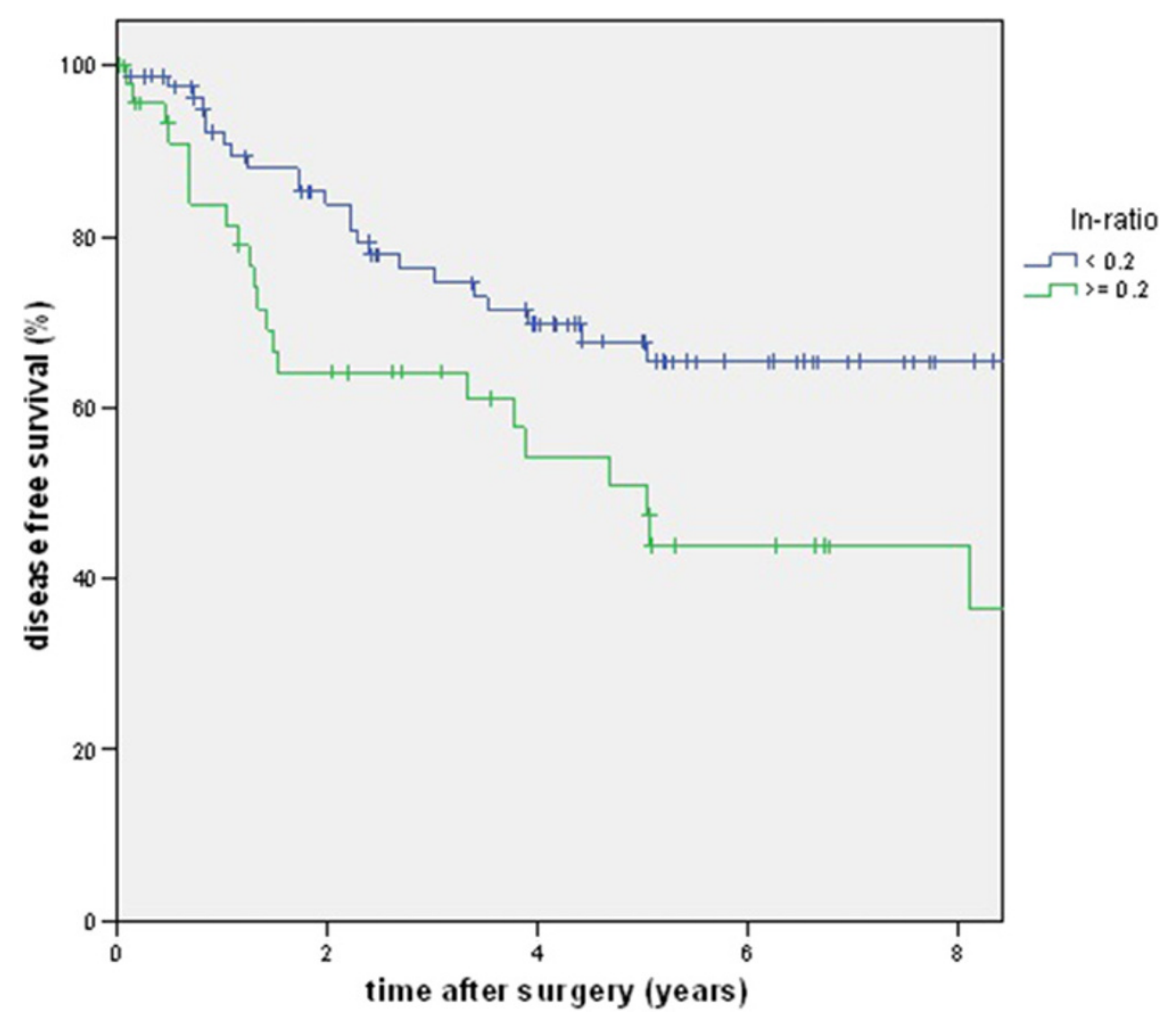

Figure 4 The figure shows the disease-free survival stratified by lymph node ratio. With a higher ratio disease-free survival (DFS) becomes worse $(P=0.008)$. 


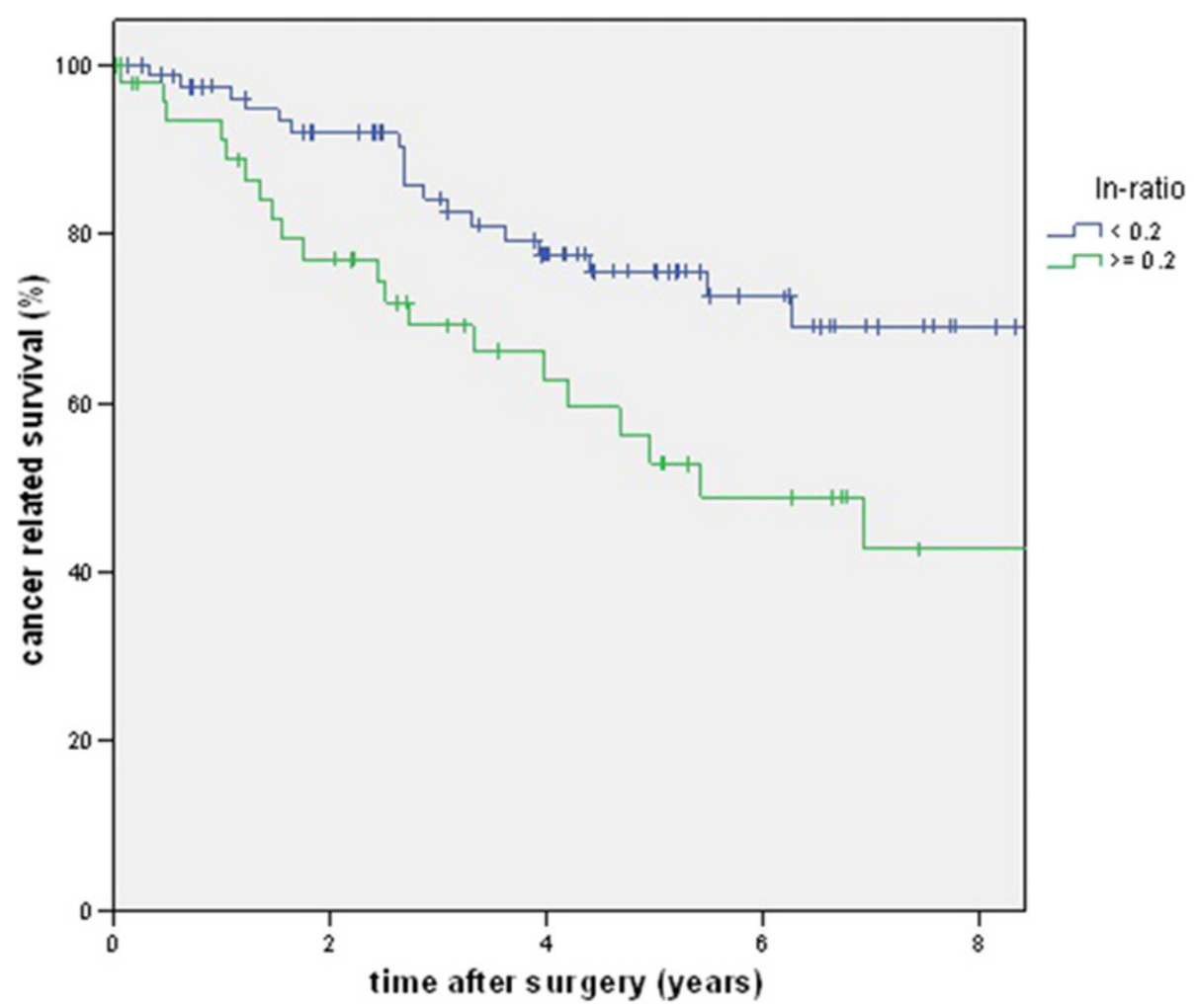

Figure 5 The figure shows the cancer-related survival stratified by lymph node ratio. With a higher ratio cancer-related survival becomes worse $(P=0.007)$.

5). But as shown in the figures and posted in Table 2, statistically, differentiation was stronger using the $\mathrm{N}$ category of the TNM system.

There is no statistical difference between $\mathrm{pN}$ category of the TNM system and the ln ratio, although the differences in our cohort are bigger for the $\mathrm{pN}$ category of the TNM system, as is shown by a lower $P$ value. It is noteworthy that 12 patients with $\mathrm{pN} 1$ were categorized in the high $\ln$ ratio group, and 20 patients with $\mathrm{pN} 2$ were categorized in the low $\ln$ ratio group.

Table 2 Comparison of lymph node ratio (LNR) and pN category of the TNM system for disease-free survival (DFS) and cancer-related survival (CRS)

\begin{tabular}{llllrc}
\hline & & DFS (\%) & Mean DFS (years) $^{\mathbf{a}}$ & $\mathbf{9 5 \% ~} \mathrm{Cl}^{*}$ & $\boldsymbol{P}$ \\
\hline \multirow{2}{*}{$\mathrm{LNR}$} & $<0.20$ & 73.9 & 7.54 & 6.60 to 8.48 & 0.008 \\
& $\geq 0.20$ & 53.8 & 5.35 & 4.05 to 6.65 & \\
$\mathrm{~N}$ & 1 & 78.8 & 8.07 & 7.13 to 9.02 & $<0.001$ \\
& 2 & 50.0 & 4.85 & 3.82 to 5.87 & \\
& & CRS (\%) & Mean CRS (years) & $\mathbf{9 5 \%} \mathbf{C l}^{*}$ & $\boldsymbol{P}$ \\
\multirow{2}{*}{ LNR } & $<0.20$ & 78.4 & 7.92 & 7.01 to 8.84 & 0.007 \\
& $\geq 0.20$ & 55.8 & 5.85 & 4.61 to 7.09 & \\
\multirow{2}{*}{$\mathrm{N}$} & 1 & 78.8 & 8.18 & 7.23 to 9.13 & 0.002 \\
& 2 & 58.1 & 5.41 & 4.53 to 6.29 & \\
\hline
\end{tabular}

astimation is limited to longest follow-up time.

\section{Discussion}

We retrospectively analyzed whether it would be beneficial to determine the lymph node ratio rather than the $\mathrm{N}$ category of the TNM system in prognosis of colon cancer. Therefore, we picked 142 stage III colon cancer patients from a cohort of 939 colorectal cancer patients who were operated on over a 10 -year period. In comparison to other reports [6], the fraction, Stage III patients in comparison to all (I to IV) patients) is rather small but the number of examined lymph nodes is rather high $[8,10]$ as is the percentage of patients receiving adjuvant chemotherapy [17].

For easier comparison of $\mathrm{N}$ stages to lymph node ratio, we decided to calculate two groups of lymph node ratios. By doing so, there is no superiority in predicting disease-free and overall survival of the lymph node ratio to the $\mathrm{N}$ category of the TNM system. Other authors split patient cohorts by random or percentiles rather than calculating groups $[6,7,9,11]$. By using more groups, the lymph node ratio gains in precision of prognosis $[6,7,11]$, but if more subgroups were established in the $\mathrm{N}$ category, precision would presumably rise there as well. So, in our opinion, the only possibility for comparing the two approaches is to use the same number of groups.

To exclude the bias of neoadjuvant treated patients, we decided not to include rectal cancer patients in the 
analysis. In rectal cancer patients, the number of pathologically diagnosed lymph nodes is frequently lowered after neoadjuvant treatment in comparison to patients not treated with neoadjuvants [18]. Therefore, all rectal cancer patients were excluded from this analysis. Other authors used a stage I to IV colorectal cancer cohort over many years to show the advantage of the lymph node ratio [11]. The disadvantage of this particular approach is that there are many patients included who do not have lymph node metastasis at all, have distant metastasis synchronously and that patients were operated over a long time period. Within this period, surgical techniques might have changed substantially, and therefore, it might be difficult to compare patients' courses of the disease.

\section{Conclusions}

Conclusively, we show with a rather simple approach, that using the lymph node ratio rather than the $\mathrm{N}$ category of the TNM system is not beneficial in terms of predicting overall and disease-free survival. Of course there will be an advantage by increasing the number of subgroups within the category - in the $\mathrm{N}$ category of the TNM system as well as within the lymph node ratio. In our consideration, there is no need to change the categorization toward the lymph node ratio.

\section{Abbreviations}

ASA: American Society of Anesthesiologists; CRC: Colorectal cancer; CRS: Cancer-related survival; DFS: Disease-free survival; In ratio: Lymph node ratio; UICC: Union for International Cancer Control.

\section{Competing interests}

The authors declare that they have no conflicts of interest.

\section{Authors' contributions}

LS and AKE conceived and coordinated the study, collected patients' data and participated in the statistical analysis. LS drafted the manuscript. MG and EK participated in preparing and drafting the manuscript. All authors read and approved the final manuscript.

Received: 4 February 2013 Accepted: 11 March 2013

Published: 23 March 2013

\section{References}

1. Gesellschaft der epidemiologischen Krebsregister in Deutschland e.V. and Robert Koch-Institut: Krebs in Deutschland - Häufigkeiten und Trends. 5th edition. Saarbrücken: Gesellschaft der epidemiologischen Krebsregister in Deutschland e.V; 2006:108-2006.

2. Staib L, Link KH, Blatz A, Beger HG: Surgery of colorectal cancer: surgical morbidity and five- and ten-year results in 2400 patients - monoinstitutional experience. World J Surg 2002, 26:59-66.

3. Davis NC, Evans EB, Cohen JR, Theile DE, Job DM: Colorectal cancer: a large unselected Australian series. Aust N Z J Surg 1987, 57:153-159.

4. Chau I, Cunningham D: Treatment in advanced colorectal cancer: what, when and how? Br J Cancer 2009, 100:1704-1719.

5. Meyerhardt JA, Mayer RJ: Systemic therapy for colorectal cancer. NEJM 2005, 352:476-487.

6. Thomas M, Biswas S, Mahamed F, Chandrakumaran K, Jha M, Wilson R: Dukes $C$ colorectal cancer: Is the metastatic lymph node ratio important? Int J Colorectal Dis 2012, 27:309-317.
7. Ceelen W, Van Nieuwenhove Y, Pattyn P: Prognostic value of the lymph node ratio in stage III colorectal cancer: a systematic review. Ann Surg Oncol 2010, 17:2847-2855.

8. Parsons HM, Tuttle TM, Kuntz KM, Begun JW, McGovern PM, Virnig BA: Association between lymph node evaluation for colon cancer and node positivity over the past 20 years. JAMA 2011, 306:1089-1097.

9. Powell AG, Wallace R, McKee RF, Anderson JH, Going JJ, Edwards J, Horgan PG: The relationship between tumour site, clinicopathological characteristics and cancer-specific survival in patients undergoing surgery for colorectal cancer. Colorectal Dis 2012, 14:1463-1469.

10. Sjo O, Merok M, Svindland A, Nesbakken A: Prognostic impact of lymph node harvest and lymph node ratio in patients with colon cancer. Dis Colon Rectum 2012, 55:307-315.

11. Rosenberg R, Friederichs J, Schuster T, Gertler R, Maak M, Becker K, Grebner A, Ulm K, Höfler H, Nekarda H, Siewert JR: Prognosis of patients with colorectal cancer is associated with lymph node ratio: a singlecenter analysis of 3,026 patients over a 25-year time period. Ann Surg 2008, 248:968-978.

12. AWMF: http://www.awmf-online.de.

13. Dripps RD, Lamont A, Eckenhoff JE: The role of anesthesia in surgical mortality. JAMA 1961, 178:261-266.

14. Wittekind C, Wagner G: TNM Classification of Malignant Tumours. 5th edition. New York: Wiley; 1997.

15. Klein JP, Moeschberger ML: Survival analysis. New York: Springer; 1997

16. Therneau TM, Grambsch PM, Fleming TR: Martingale based residuals for survival models. Biometrika 1990, 77:147-160.

17. El Shayeb M, Scarfe A, Yasui Y, Winget M: Reasons physicians do not recommend and patients refuse adjuvant chemotherapy for stage III colon cancer: a population based chart review. BMC Res Notes. 2012, 5:269.

18. Doll D, Gertler R, Maak M, Friederichs J, Becker K, Geinitz H, Kriner M, Nekarda H, Siewert JR, Rosenberg R: Reduced lymph node yield in rectal carcinoma specimen after neoadjuvant radiochemotherapy has no prognostic relevance. World J Surg 2009, 33:340-347.

doi:10.1186/1477-7819-11-79

Cite this article as: Schiffmann et al: Is the lymph node ratio superior to the Union for International Cancer Control (UICC) TNM system in prognosis of colon cancer?. World Journal of Surgical Oncology 2013 11:79.

\section{Submit your next manuscript to BioMed Central and take full advantage of:}

- Convenient online submission

- Thorough peer review

- No space constraints or color figure charges

- Immediate publication on acceptance

- Inclusion in PubMed, CAS, Scopus and Google Scholar

- Research which is freely available for redistribution 